\title{
Creació literaria
}

\author{
BÁRBARA SÁEZ ${ }^{1}$
}

\section{Daleninar y su pequeña historia. Imaginando una vida en el litoral peninsular Mediterráneo en el siglo IV a.C., entre los poblados y las gentes que los griegos denominaban iberos}

\author{
Daleninar and her Little History. \\ Imagining a life on the Mediterranean peninsular coast \\ in the 4th century $B C$, among the settlements and the \\ folk the Greek called Iberians
}

Daleninar permanecía en el centro de la pequeña estancia. Estaba de rodillas sobre las desdibujadas improntas de la tierra prensada y muy pegada a las brasas que habitualmente intentaban atenuar la humedad de los últimos fríos. De pronto, se abrió la cortina de la entrada que daba al patio. El humo que envolvía a Daleninar la ocultó por un momento, aunque la claridad del exterior no tardó en enfocar directamente la llamativa imagen de su rosto.

—iPero qué te has hecho? -le gritó Aretaunin muy alterada.

Daleninar no le respondió aunque sabía que su suegra le preguntaba por la gran quemadura que le cruzaba la cara. Su herida iba desde la mejilla izquierda hasta la ceja. No podía hablar pues estaba concentrada en contener un grito de dolor a la vez que mantenía una mirada de desafío. Después, empezó a marearse y tuvo que bajar la cabeza. Finalmente soltó frente a ella el cuchillo con el que se acababa de marcar la piel a fuego.

Al ver la herida de Daleninar, Aretaunin entendió al instante lo que aquella quemadura significaba para ella misma, y se enfureció. Tembló de rabia cuando entró en la estancia y dejó caer la cortina tras ella. Después, se quedó un instante de pie entre la penumbra de una lámpara de aceite con su respiración contenida y la furia que se le removía por dentro. Respiró hondo y se acercó hasta el banco de la pared del fondo y buscó a tientas cualquier objeto que le sirviera para su propósito. No tardó en palpar sobre el banco, colgado en el zócalo de piedra y justo antes del nacimiento del muro de adobe, el cinturón de cuero, con una gran hebilla de bronce, con el que su hijo azotaba a su mujer. Cuando Aretaunin se volvió hacia Daleninar, su nuera ya estaba recogida y preparada para recibir los golpes.

Con la cabeza entre las rodillas y con las manos colocadas para proteger su nuca, pese al dolor, Daleninar no se quejó ni en uno solo de los azotes, patadas y golpes que recibía de su suegra mientras le pedía a Madru poder terminar con el suplicio que era su vida.

1 Universitat Jaume I de Castelló. 
Daleninar creció aislada del mundo exterior. Nació en Hibera donde, huérfana de madre, se crió en la gran casa de su padre junto a su hermano mayor. Pero, al contrario que a este, ella creció encerrada. No le permitían salir a correr libremente por las calles. Ni siquiera podía permanecer bajo la luz directa del sol en el patio interior de su casa. No le dejaban realizar ninguna actividad que le tostara la piel. Esto podría hacerle perder valor cuando llegase el momento de entregarla en matrimonio. Por ello, Daleninar se pasaba el día a la sombra, obligada a blanquearse los dientes y la piel con pasta de orina seca y a tomar los baños de aceite que le preparaban las esclavas. Para otras jóvenes afortunadas, también hijas de prósperos comerciantes, no era tan importante mantener una imagen perfecta y no vivían encerradas. La vida de las gentes en Hibera era sencilla y la elección de una esposa no se basaba en la apariencia sino en asegurar el mejor trato que beneficiara a su familia. Pero, desde niña, Daleninar era conocida por la atracción que sus involuntarios movimientos y su mirada ejercían sobre los hombres. Su padre pretendía aprovechase de la leyenda creada en torno a su hija y la ocultaba como a un tesoro. Conocedor de su valor, incluso les pidió a las criadas que le racionaran la comida en cuanto llegó el momento en que Daleninar recogió sus trenzas bajo el velo que cubría su pelo pues su cintura no podía exceder de cierta medida para ser bien considerada. Su padre tenía grandes planes para su vejez que únicamente alcanzaría si entregaba a su hija a una familia lo bastante influyente.

Daleninar siempre estaba sola. Apenas recibía visitas y fueron muchas las criadas que, con la mirada baja, se encargaron de su cuidado. Veía muy poco a su hermano y no recordaba si alguna vez su padre le había mirado a los ojos. Este era un frío comerciante de lana que trataba con la colonia griega en Ampurias. Los tejidos confeccionados en sus tierras eran muy apreciados y sus intercambios eran abundantes. Con ellos, acumulaba oro y favores en los tratos que cerraba frente a la gran losa de la pared del interior del templo de Saitabi. Así, las únicas veces que Daleninar salía de casa era cuando su padre le permitía seguirle, dos pasos por detrás, en sus visitas a este templo. Con la excusa del interés que la muchacha mostraba por la diosa de la naturaleza, por Madru, su padre aprovechaba para exponerla estratégicamente ante determinados hombres acaudalados. Daleninar era una simple mercancía en busca del mejor trato. Ella lo sabía, pero no le importaba. Prefería la sensación de sentirse observada por los ojos de malolientes y libidinosos que fundirse en el aburrimiento de los monótonos muros de su patio.

El templo era una pequeña edificación junto a la muralla. Un empedrado en la entrada y un estrecho pasillo accedía hasta una gran puerta de madera. El interior estaba cubierto y se iluminaba con lámparas de aceite. En el centro, una gran piedra hexagonal estaba permanentemente cubierta de ofrendas. Los comerciantes se repartían por las esquinas en grupos de conversaciones cruzadas mientras Daleninar se arrodillaba junto a los sacerdotes. Ultiteceraicase era el más anciano y también quien más la apreciaba. El sacerdote olía a hierbas frescas, tenía media cabeza rapada, llevaba pendientes enormes con forma de luna creciente, un gran anillo, varios brazaletes y muchos collares, además de una larga túnica con volan- 
tes en la parte baja. Él era quien, cada rato que Daleninar era exhibida, le susurraba lecciones para que pudiera comunicarse con Madru de la manera adecuada, para que apreciara correctamente el color de las nubes o para que entendiese las consecuencias de la llegada del aire cálido. A Daleninar le encantaba aprender en su voz amable pues la diosa era su única compañía cuando volvía a casa y se quedaba de sola.

Una mañana, como tantas otras, Daleninar oyó a su padre pedirle a las criadas que la prepararan para acompañarle. Pero en esa ocasión, ordenó que le pusieran el manto más blanco y brillante, con las cenefas más definidas y que ella misma tejiera en los extremos. Al principio y por la época, pensó que su padre pretendía que ella volviera a presentarse en el concurso de la cosecha. Esta era la celebración más importante del poblado. Las mujeres mostraban ante un grupo de hombres notables sus mejores tejidos y, de entre todas, elegían a la que más cantidad y calidad de telas había presentado. Era algo muy importante socialmente y que daba categoría a la familia de la ganadora. Pero, aunque Daleninar había ganado las dos últimas veces, no se sentía orgullosa. Creía que hacía trampa. El resto de jóvenes y mujeres trabajaban todo el día en el campo desde la salida del sol, molían el grano y preparaban la comida mientras sus maridos se sentaban a desarrollar sus oficios. Ella no tenía nada que hacer más que deshacer sus errores y volver a tejer hasta encontrar la perfección. Sin embargo, en cuanto salió detrás de su padre y de su hermano, supo que aquello no tenía que ver con ningún concurso.

Frente a la casa de su padre, y ante la mirada curiosa de dos ancianos sentados en el banco adosado a su vivienda, Daleninar se encontró expuesta, como una bestia, al examen de un gran hombre de mirada cruzada. Sintió la aspereza de su mano en el cuello. Le levantó la cabeza y ella notó el sabor de la suciedad de sus dedos cuando le apartó la lengua para mirarle las muelas. Después, se quedó quieta mientras aquel hombre llamó a una mujer que se acercó a ella decidida. La mujer iba cubierta con un pesado manto de lana, pese al calor, se puso de rodillas frente a Daleninar y escarbó entre las capas de su atuendo hasta llegar sin delicadeza a su sexo. Le hizo daño, pero Daleninar no gritó cuando la vio sacar su mano sangrante de virginidad. Aquella mujer, a quien el hombre llamó Aretaunin, se puso en pie y lamió la sangre de sus manos sin dejar de observarla. Parecía que quería intimidarla. No sabía que Daleninar agradecía la mirada directa de alguien, aunque fuese la de una fiera. Al entenderlo como un desafío, Aretaunin acabó enfadada ante la fuerza y la impasibilidad que transmitía su mirada.

Enseguida marcharon al templo. Al entrar Daleninar se quedó extrañada. Esa mañana no había comerciantes, solo estaba Ultiteceraicase, el viejo sacerdote, y un joven de aspecto enfermizo. A pesar de su debilidad, intuyó que de aquel chico se escapaba la misma mirada ruin y cruel de quien, por su gran parecido, era indudablemente su madre, Aretaunin. El chico miró descarado la figura voluminosa con la estrecha cintura de Daleninar, sus pechos marcados a pesar del manto y su piel fina y extremadamente blanqueada. Empezó a resoplar como un asno cegado de hormonas recién despertadas. Su madre miró gustosa el deseo que emanaba de los ojos de su hijo sobre quien se iba a convertir en su esposa. 
Daleninar estaba frente al altar al lado de aquel joven grotesco y, a pesar de la malicia que emanaba de su futura familia, observaba la escena intrigada por los cambios en su vida. En su inocencia, agradecía acabar con el tormento del aburrimiento de su rutina. Todavía no sabía cuánto iba a echar de menos la soledad y la tranquilidad que había gobernado sus días desde niña. Cuando Ultiteceraicase terminó de hacer las ofrendas, no le extrañó que su padre no se despidiera de ella. La última vez que Daleninar oyó su voz fue dentro de templo. Estaba centrado en los detalles de sus nuevos acuerdos con Saitabi.

El reciente marido de Daleninar era el único hijo del mayor depositario y distribuidor de cerámica de lujo y abalorios que traían los grandes barcos desde Grecia, pero, aunque ya tenía edad suficiente, estaba demasiado enfermo para hacerse cargo de los negocios de su padre. Este último era un hombre caprichoso, derrochador y, sobre todo, alguien a quien le gustaba lucir y jactase de su poder. Su mujer, Aretaunin, temía que si su hijo moría su marido se buscara otra esposa con la que conseguir descendencia para su linaje. Sabía que necesitaba urgentemente un nieto para no ser repudiada. Por ello, Aretaunin le había rezado a Madru encontrar a una mujer fuerte y sana para compensar todas las deficiencias de su hijo. Ella ya no era joven, había sobrevivido a muchas de sus primas y vecinas, pero todavía se sentía con fuerzas para criar un nieto, ponerlo de su lado y así tener una vejez tranquila bajo su protección. Los comerciantes itinerantes iban arriba y abajo de la costa y acostumbraban a visitarla. A cambio de que Aretaunin adquiriera alguna pequeña pieza, joya o piel curtida, ellos le contaban al detalle toda clase de historias y rumores. Así fue como oyó hablar de Daleninar, conocida como la joven sacerdotisa del templo de Hibera a la que Madru había concedido todos los dones de la naturaleza. Daleninar era perfecta para su hijo.

Llegaron a su gran casa en Saitabi tres días después de su marcha. A Daleninar le encantó ver el mundo en directo a pesar de la dureza de los caminos. En cambio, el viaje fue muy duro para su nuevo marido. A pesar de su interés por culminar su matrimonio, el joven estaba tan debilitado que no pudo ni intentarlo. Así, el viaje fue una experiencia feliz y novedosa para Daleninar, aunque, tras los primeros días, dejó de sonreír los cambios en su vida. Se encontró encerrada como en la casa de su padre. Allí tampoco nadie la miraba a los ojos y además le mandaban y le gritaban sin razón justificada. Su suegra odiaba y temía, en la misma proporción, su aire inteligente y acostumbraba a pegarle al mínimo error. Daleninar ya no tejía sino que era la encargada de limpiar la lana y de enrollarla para que Aretaunin pasara las tardes con las vecinas chismorreando frente a sus grandes telares en la calle. Por las noches, lloraba. Lamentaba su vida miserable y se odiaba por su comportamiento en la casa de padre. Por entonces, solo se quejaba de su soledad, jamás pensó en la labor de las esclavas a las que ella nunca miró a los ojos. Como ellas, en la casa de su marido Daleninar no tenía libertad y se movía a voluntad de sus amos.

Una noche de luna menguante, un esclavo entró a despertar a Daleninar al dormitorio de las mujeres. Dormía sobre una esterilla de esparto, no como la mullida y limpia lana de la casa de su padre. Le hicieron entrar en una pequeña estancia con olor a humedad y una tibia lámpara que iluminaba los ojos lujurio- 
sos de su marido. Daleninar no comprendió de dónde sacó aquel chico enfermizo el genio con el que la atacó, la tiró al suelo, le levantó la falda y la penetró. Había vivido aislada y jamás había visto ni oído nada parecido a lo que su marido le hizo. Aquello le pareció un horror. Cuando la devolvieron a su habitación, una criada de ojos claros, un par de primaveras menor que ella, entendió por experiencia su desconcierto y, la pobre chica, se lo explicó. A la mañana siguiente, su suegra le advirtió que, cada noche, atendiera gustosa a los deseos de su hijo y que le rezara a Madru para quedarse encinta. De este modo, Daleninar pasó los días ahumando la carne, acarreando la leña, desgranando y moliendo de rodillas en el patio de su nuevo encierro mientras que, por las noches, lloraba dolorida tras los encuentros con su marido. Con los días, ella se encontró cada vez más débil porque su marido era cada vez más cruel. La razón era que el joven notaba que, aunque Daleninar pretendía dominarse para no hacerlo enfadar, una fuerza interior le despreciaba y se rebelaba a su intento de someterla. Daleninar pasó mucho tiempo rezando a Madru para que su marido se muriese pronto y llegó a estar tan desesperada que pensó en matarlo ella misma. Pero, pese a su constante tortura, su juventud no le permitía ir en contra de lo que Ultiteceraicase, el sacerdote del templo de Hibera, le había enseñado. Este había sido su único amigo y le había susurrado el respeto que exigía Madru ante el agua, la luz, los animales y los hombres. Pero no sabía cuánto tiempo podría aguantarlo y decidió tomar medidas. Se arriesgó a hablar con la criada de ojos claros para que le consiguiera una mezcla de esencias que recordaba del templo. Se las administró en las comidas a su marido diluidas en el vino. Estaba tan enfermo que a nadie le sorprendió que se pasase el día dormido hasta que, al fin, una mañana Madru ya no le dejó despertar. En la cremación de su cuerpo, Aretaunin, su madre, lloró su muerte más desesperada por la falta de embarazo de su nuera que por su ínfimo instinto maternal. Aretaunin sabía que ese era su fin. Iba a ser repudiada de manera inmediata por su marido. Sería expulsada del poblado como hacían con las ratas que inundaban las cabañas de los animales. Pero entonces, su mente despierta y avispada tuvo otra idea. Debía convencer a su marido de que yaciera con Daleninar hasta dejarla preñada. Si lo hacía rápido, nadie cuestionaría que el padre era su hijo fallecido. De este modo, su marido tendría su descendiente y ella permanecería como matrona de la casa. Pero este era un hombre duro y despectivo que la detestaba abiertamente y Aretaunin tuvo que esperar unos días hasta que una tarde su marido llegó cansado y con el genio calmado. Entonces le sacó su mejor vino de las islas, aquel que tenía guardado para ocasiones. Después de servirle dos grandes vasos, le dio a comer carne asada de ciervo que había conseguido en un intercambio desventajoso pero necesario. Volvió a servirle otro vaso antes de contarle su plan. Al principio, su marido rechazó de plano su propuesta. Este acostumbraba a encapricharse de jóvenes de procedencias, acentos y cabellos lejanos que utilizaba hasta que se hartaba de sus rarezas. Únicamente gracias a ellas soportaba la relación con Aretaunin. Pero, tras la muerte de su único hijo, había iniciado tratos con el padre de una muchacha para afianzar el comercio en Arse y además asegurarse la descendencia. Sin embargo, tras otra copa, acabó 
cediendo ante las certeras y aduladoras palabras de su mujer tentado por el deseo sexual que siempre había sentido hacia Daleninar.

En apenas unas lunas, Daleninar había dejado de ser una joven ingenua. Comprendió rápidamente las intenciones de su suegra y tembló de horror al imaginarse a solas con su suegro. Este era un hombre igual de dañino que su marido fallecido pero con más fuerza y tiempo para poseerla, doblegarla y someterla a su voluntad. Estaba realmente desesperada. Pero una mañana estaba en el patio y, mientras separaba la lana, oyó como un joyero itinerante le contaba los últimos cotilleos de los caminos a su suegra. De entre todos, le llamó la atención la historia de un pintor de cerámica en Ildubili, un poblado muy pequeño y bastante alejado de Saitabi. Aquel hombre estaba muy aturdido por la muerte de su esposa y su hermana le buscaba una nueva mujer sin hijos para que le hiciera compañía. Su esposa había fallecido con los fríos del invierno y el hijo del jefe del poblado pretendía casarse con su hija mayor. Tenía otro hijo más pequeño y esperaba a que llegara una nueva mujer a la casa para celebrar ese matrimonio. Al oír su historia, a Daleninar se le ocurrió una idea para escapar de los muros que le estaban arrancando la vida.

Cuando el orfebre se levantó para marcharse, Daleninar se alzó y simuló ir a buscar agua de la gran tinaja de la puerta de la entrada. En cuanto creyó estar fuera de la vista de Aretaunin, corrió despavorida calle abajo.

— ¿Has dicho que ese pintor estaba muy aturdido por la muerte de su mujer? — preguntó Daleninar sin aire en los pulmones cuando alcanzó al joyero.

-Sí ¿por qué? - preguntó el hombre extrañado.

-Eso es que la apreciaba. Ese hombre debe ser buena persona cuando su hermana se interesa tanto por él ¿no? — preguntó esperanzada.

—Eso no lo sé — respondió el joyero confundido.

— ¿Cuándo vuelves a Ildubili? -le preguntó Daleninar muy interesada.

- Voy para allá, Nisunin, la matriarca de la casa de las conchas, me está esperando.

-Tienes que decirle a la hermana de ese pintor que mi suegra te ha dicho que tiene una viuda sin hijos para él y que se trasladará a Ildubili antes de la siguiente luna - le dijo Daleninar decidida.

— ¿Y por qué iba a mentir? —volvió a preguntar entendiendo que había algo raro.

Daleninar se quitó una de las tres pulseras de oro que antes fueron de su madre y se la entregó. Inmediatamente después, volvió corriendo hacia la gran casa para intentar llegar antes de que Aretaunin notara su falta.

Fue a la mañana siguiente cuando Daleninar bajó y cogió un cuchillo mellado de la despensa. Decidida, fue a la habitación de su difunto marido y lo puso en las brasas de un fuego que ella misma había traído antes del amanecer. Después lo levantó, lo miró fijamente y, finalmente, se quemó la cara con aquel cuchillo. Daleninar conocía las preferencias por las jóvenes de su suegro y también las ganas que tenía de deshacerse de su mujer. Sabía que en cuanto la mirara a la cara quemada, tendría una excusa para rechazar el trato con Aretaunin que había aceptado demasiado ebrio. Aretaunin también lo sabía y por eso descargó sobre Daleninar toda su rabia. 
Con la cabeza entre las rodillas y con las manos colocadas para proteger su nuca, pese al dolor, Daleninar no se quejó ni en uno solo de los azotes, patadas y golpes que recibía de su suegra mientras le pedía a Madru poder terminar con el suplicio que era su vida. La paliza fue tan tremenda y dura como Daleninar esperaba, tanto que Aretaunin la dio por muerta en la oscuridad de la estancia y en el olor a piel quemada. Después mandó que tiraran su cuerpo a las afueras del poblado.

Los viajantes, campesinos y vecinos salían por las puertas del Saitabi, cruzaban el cementerio de sus ancestros y murmuraban al ver, un poco más allá, el cuerpo de Daleninar tirado en la tierra boca abajo. Todos pensaban que estaba apedreado. Era costumbre lapidar a las mujeres adúlteras y dejar su cuerpo para los animales. No se les permitía ser incineradas para que sus espíritus no se reunieran de nuevo con Madru. No fue hasta la noche cuando Daleninar despertó dolorida, rota y amoratada. La herida de la cara le ardía pero se alegraba de no estar muerta. Buscó entre sus ropajes y comprobó que todavía tenía el ungüento y la comida que había preparado para la huída, pero no tenía agua. Se levantó y empezó a alejarse en dirección norte. Pretendía llegar viva a la fuente del cruce de caminos y para ello le rezó a Madru a cada paso. Cuando, después de mucho arrastrar sus pies, lo consiguió, se lavó en la fuente la cara y las heridas. Se curó con trozos viejos del fino hilo de su túnica interior. Al arrancarlos, recordó que su padre le dio personalmente ese pliegue de tela y, por primera vez, sintió verdadera añoranza de su casa. Recordaba el día que se lo dejó en la entrada de su dormitorio y también que, egoístamente, ella no se lo agradeció porque estaba molesta de que él no le hablara. Daleninar se quedó escondida en uno de los lados del santuario. Durmió todas las horas de varios días. Estaba tan malherida que algunos de los oferentes a Madru se compadecieron de ella y le ayudaron. Por fin, una tarde recuperó las fuerzas para caminar oculta de noche y para dormir de día hasta arribar a las puertas de Ildubili.

Ildubili era un pequeño enclave protegido por lienzos de murallas encaladas que relucía sobre una montaña hexagonal. Como Daleninar, aquel pequeño poblado no se conformaba con sobrevivir, sino que intentaba levantarse y presidir con orgullo el dominio de sus campos frente al mar. Entró por la puerta norte en sus calles estrellas. Antes de llegar al cuerpo de guardia, Daleninar se quitó el polvo del manto e intentó tapar con el velo la quemadura de la cara. Los dos soldados de la entrada la miraron con curiosidad pero la dejaron entrar cuando ella les preguntó dónde vivía el pintor de cerámica. Al caminar entres aquellas calles, vio que no había puertas de madera en las entradas a las viviendas y que unas sencillas cortinas resguardaban de la intemperie las posesiones de sus gentes. No circulaban por ellas los carros, los animales o la cantidad de gente que se oía desde los patios de Hibera o Saitabi. Las casas ni quisiera tenían patio y apenas había un par de bancos adosados a los muros. De repente, el viento levantó sus ropajes y las nubes llegaron tan rápido como algunas mujeres corrían a sus hogares a esconderse de lo que se anunciaba en los truenos del fondo. Daleninar avanzaba pausada y encantada de sentir el viento en su cara y de es- 
cuchar el sonido de la fuerza con que Madru gritaba desde el cielo. Avanzó decidida sobre el grueso empedrado bajó la lluvia que empezó a caer a raudales. El agua se llevó calle abajo toda la suciedad que los vecinos habían acumulado en las puertas de sus viviendas durante dos lunas de sequía. Daleninar estaba empapada y feliz de avanzar libremente hacia un destino que, bueno o malo, ella misma había elegido.

Daleninar llegó hasta el bajo de una vivienda donde un hombre, alto y de espaldas anchas, intentaba recoger las piezas de cerámica para resguardarlas de la lluvia.

- ¡Corre Lagunas! ¡Guárdalo todo! —le gritó el hombre a un niño.

A pesar de sus gritos, el pintor se movía lento. Daleninar no había conocido a muchos hombres durante su vida, pero reconocía que aquel estaba desconsolado por un dolor profundo que, como a ella, lo había dejado marcado.

De pronto, Abartiaigis pareció percibir su presencia y se volvió despacio hacia ella.

—Soy Daleninar, me envía... —empezó a decir con voz temblorosa-. Traigo esto para cumplir mi aportación para nuestra unión.

Daleninar le enseño los dos finos brazaletes que le quedaban en el brazo.

—Eres más joven de lo que imaginaba, ¿has venido sola? — preguntó Abartiaigis extrañado sin mirar las joyas-. ¿Y esa quemadura?

Ella no respondió, no podía contarle la verdad pero no quiso mentirle. Abartiaigis la miraba a los ojos tan fijamente que creyó que la iba a descubrir. Le resultó extraña la sensación que le trasmitió su mirar cálida.

—Sube, debes resguardarte — dijo Abartiaigis señalando las escaleras exteriores que subían al piso de arriba.

Daleninar suspiró aliviada y subió por los escalones. El niño la siguió y, cuando llegó al humilde rellano del que iba a ser su hogar, Lagunas la cogió de la mano y la invitó a entrar.

En el último paso, Daleninar se volvió de nuevo hacia Abartiaigis y, justo entonces, vio escaparse de un lado de la boca de aquel hombre grande y gastado una especie de tibia sonrisa que ella comprendió enseguida. Fue un gesto cansado, breve, sincero y limpio con la que agradecía interiormente a Madru el haber mejorado su vida. 